\title{
EVOLUÇÃo do PIB DA CADEIA PRODUTIVA DO ALGODÃO NA DÉCADA DE $2000^{1}$
}

\author{
Arlei Luiz Fachinello² \\ Adriana Ferreira Silva ${ }^{3}$ \\ Geraldo Sant'Ana de Camargo Barros ${ }^{4}$
}

\section{Resumo}

A década de 2000 marcou um importante ciclo de crescimento na economia brasileira, finalizando, porém, com a crise financeira de 2009. Na cadeia produtiva do algodão, transformações estruturais do lado da produção e a maior abertura comercial impuseram mudanças competitivas no mercado, condicionando importantes ajustes. Para entender o impacto desse cenário, o presente artigo realizou o cálculo do PIB da cadeia produtiva do algodão, entre os anos de 2001 e 2011, explorando as mudanças observadas em cada segmento da cadeia. Os resultados apontaram perdasa partir de 2004, com aumento expressivo da participação do setor primário no valor agregado, enquanto o produto industrial perdeu renda e participação no conjunto da cadeia.

Palavras-chave: algodão, cadeia produtiva, renda.

Classificação JEL: Q13.

\section{INTRODUÇÃO}

Desde a revolução industrial, no século 19, o setor têxtil teve papel importante na geração do produto e empregos nacionais ${ }^{5}$. Ao longo das úl-

Este trabalho é resultado de pesquisa realizada pelo Cepea/Esalq/USP, com apoio financeiro da Confederação Nacional da Agricultura.

Professor do Departamento de Economia e Relações Internacionais da UFSC

Pesquisadora do Centro de Pesquisas Econômicas Aplicadas - CEPEA/USP

Professor do Departamento de Economia Administração e SociologiaEscola Superior de Agricultura Luiz de Queiroz-ESALQ/USP.

Canabrava, Alice Piffer. O Desenvolvimento da Cultura do Algodão na Província de São Paulo, | 86 | - | 875. São Paulo: Martins, 1951. 
timas décadas, a globalização dos mercados mundiais trouxe à tona novos desafios para as indústrias inseridas neste setor. Para a indústria brasileira, a entrada de novos concorrentes mais competitivos ampliou as dificuldades e expôs as fragilidades do setor.

Os anos de protecionismo com as políticas de substituição de importações no paísdeixaram a indústria têxtil brasileira tecnologicamente defasada e em condições adversas de competir com os produtos estrangeiros. Já no fim da década de 1980, o parque têxtil mudou consideravelmente, destacando-se, além da modernização tecnológica e organizacional, o deslocamento da atividade industrial para a Região Nordeste do país em busca da redução de custos.

A estabilidade econômica em seguida contribuiu para os empresários modernizarem seus parques produtivos, mas não sem sentir o efeito da entrada de produtos asiáticos a um preço muito menor que o nacional. Houve grande fechamento de empresas e redução de empregos. A entrada dos anos 2000 foi marcada pela desverticalização da produção e o aparecimento de pequenas empresas operadas por antigos funcionários de grandes empresas para prestação de serviços. (HENSCHEL, 2002; FERNANDES, 2008).

Mesmo diante dos ajustes produtivos e das perdas relativas de participação do produto nacional, osetor têxtilsegue com papelrelevante na economia brasileira. Segundo a Associação Brasileira da Indústria Têxtil e de Confecção (ABIT), em 2011, a cadeia de têxteis e confecções, composta por 30 mil empresas formais,faturouUS\$ 67 bilhões e empregou cerca de 1,7 milhõesde trabalhadoresdiretos no país, sendo a segunda maior atividade na geração de empregos diretos no país. Em relação à indústria de transformação, o setor representou $16,4 \%$ dos empregos e 5,5\% do faturamento.

No segmento primário a produção de fibras naturais também vem crescendo, alimentada porum conjunto de fatores, desde os constantes aumentos do preço do petróleo e derivados, até as preocupações e exigências ambientais, que revalorizaram as fibras naturais. O país é, atualmente, o $4^{\circ}$ produtor mundial, com 7,6\% do total de 27,6 milhões de toneladas. Quanto ao consumo, o Brasil figura na $5^{\text {a }}$ posição mundial, com $4,1 \%$ das 25,8 milhões de toneladas (ABIT, 2011).

A expansão da cotonicultura foi fortemente influenciada pelo aumento da produtividade, mas a área de cultivo ainda é um fator importante para explicar o comportamentoda produção no país. Seu pólo produtivo deslocouse do Sudeste para o Centro-Oeste. Estamudança permitiu o crescimento 
da área cultivada e a substituição de um modelo produtivoobsoleto, com baixa produtividade, por um modelo agrícola empresarial de melhordesempenho, praticado em grandes extensões, capitalizado e tecnificado. Como resultado, os estados do Mato Grosso, Bahia e Goiás assumiram aliderança na produção nacional de algodão em detrimento de São Paulo e Paraná, tradicionaisprodutores.

Diante dessas transformações econômicas na cadeia produtiva do algodão, com perdas significativas no produto e mais recentemente com demanda por políticas que elevem a competitividade do setor industrial, um estudo do comportamento da renda gerada na cadeia do algodão surge como um meio de entender a dinâmica desta atividade e de seus elos, desde a compra de insumos, a produção do algodão, o processamento e distribuição dos produtos.

Propõe-se, nesse artigo, a geração de estatística do PIB na cadeia produtiva do algodão no Brasil e a análise da sua evolução entre os anos de $2001 \mathrm{e}$ 2011. O PIB calculado reflete a melhora ou piora das condições econômicas das pessoas - sem distinção entre patrão e empregado (e também de qualificação ou função) - que vivem da cadeia em estudo. Assim, um PIB maior significa que potencialmente todos os que vivem ou dependem da cadeia do algodão poderão ter melhorado de vida, do ponto de vista econômico.

O estudo detalhado da renda da cadeia produtiva aparece, portanto, como uma ferramenta fundamental no entendimento da dinâmica do setor, de suas contribuições sociais e econômicas. Ademais, pode ser empregado como suporte à formulação de políticas públicas voltadas ao seu desenvolvimento, bem como sua integração eficiente aos demais setores da economia.

O texto conta, além desta introdução, comuma apresentação da metodologia empregada para a análise da renda da cadeia, de seus segmentos e dos dados utilizados; a demonstração dos resultadose, por fim, as conclusões.

\section{METODOLOGIA}

\subsection{Definições Metodológicas}

A renda, ou também PIB da cadeia, é medida pelo valor adicionado avaliado a preços de mercado. Sob tal ótica, a cadeia produtiva é constituída por quatro segmentos: (a) insumos para a produção agropecuária, (b) produção agropecuária básica, ou, como também é chamada, primária ou 
de "dentro da porteira", (c) agroindústria e (c) distribuição. Esse valor adicionado é o PIB do segmento referido e é obtido a partir da diferença entre o Valor Bruto da Produção (volume produzido vezes preço de mercado) e o consumo intermediário, ou seja, de bens e serviçosque desaparecem ao serem transformados completamente no produto no período considerado.

\subsection{Criação da base de dados para o PIB das Cadeias}

A partir do conceito da cadeia e da definição metodológica do PIB descrita no tópico 2.1, elaborou-se os procedimentos para cálculo do PIB da cadeia produtiva do algodão.

Inicialmente foram levantadas as Tabelas de Recursos e Usos (TRUs), contempladas no Sistema de Contas Nacionais publicadas pelo IBGE, para o ano de 2007. Tais matrizes descrevem o fluxo de bens e Distribuição na economia, bem como a estrutura de produção e uso, segundo atividades e setores, além de geração de renda e emprego associados às atividades. A partir das TRUs, construiu-seo conjunto "Matrizes de Insumo-produto (MIPs)" para o ano base 2007.

Vale ressaltar que a instituição responsável por gerar as MIPs da economia brasileira é o IBGE. A divulgação desse tipo de material não mantém periodicidade definida. Portanto, cabe aos pesquisadores envolvidos em analisar a economia brasileira a partir de Matrizes Insumo-produto a tarefa de gerar suas próprias estimativas. Existem diferentes metodologias para estimá-las, que podem ser encontradas na literatura especializada. No presente trabalho, foram realizadosos procedimentos sugeridos por Guilhoto e Sesso Filho (2005).

Tomando-se como base os 56 setores/atividades produtivos apresentados nas TRUs do IBGE, foram desagregadas/criadas novas atividades produtivas visando-se alcançar os objetivos do trabalho. A criação destas atividades envolve a obtenção do máximo de informações disponíveis que orientem a tomada de decisão sobre destino dos produtos e estrutura das despesas. Devido às especificidades envolvidas, cada atividade foi analisada separadamente em função de suas características, não havendo, portanto, um procedimento único na desagregação. Partindo-se do setor Agricultura já existente, desagregou-se a atividade de algodão. No grupo de atividades industriais, foi necessária a criação da atividade de Têxteis de Fios Naturais 
a partir do setor Têxtil (que é composto por fios sintéticos e naturais, em conjunto). As demais atividades de processamento ligadas à cadeia produtiva do algodão já existiam na estrutura apresentada pelo IBGE.

A próxima seção dedica-se a descrever, de forma detalhada, a formação teórica e a composição dos segmentos do PIB da cadeia do algodão.

\subsubsection{PIB dos Insumos}

O PIB do segmento de Insumos é formado por uma parcela do PIB de cada setor da economia, conforme definido pelo IBGE, supridor da respectiva cadeia produtiva em apreço. É, portanto, a soma das frações da produção de cada setor econômico que é adquirida pela atividade ou cadeia de interesse. Pode-se expressar o valor da renda do segmento de Insumos para a cadeia da seguinte forma:

$$
P I B^{I}=\sum_{i=1}^{n}\left[c t_{i} \times V A_{i}\right]
$$

em que $i \in I$ são os setores do segmento de insumos (I); $c t_{i}$ são coeficientes técnicos de uso de cada insumo procedente do setor $i$ pela atividade primária (cultivo do algodão em caroço), sendo $c t_{i}=z_{i} / X_{i}$, em que $X_{i}$ é o valor total da produção do setor $i$ e $z_{i}$ é o valor do produto do setor iadquiridopela atividade primáriado algodão. Finalmente, $V A_{i}$ é o valor adicionado do setor fornecedor de insumos $i$. No grupo de setores fornecedores de insumos (I), só estão incluídos os segmentos produtores de bens.

Ressalta-se que no segmento de Insumos não são computados insumos advindos do próprio setor (primário e/ou agroindustrial), caso houver. Dessa forma, insumos originários da agropecuária, excetuado o caso de sementes, são incluídos no segmento da agropecuária e não no segmento de insumos.

\subsubsection{PIB do segmento primário}

O PIB primário ("dentro da porteira") da cadeiainclui integralmente o valor adicionado a preços de mercados da agricultura, como explicitado abaixo:

$$
P I B_{\text {primário }}=V A_{\text {agricultura }}
$$




\subsubsection{PIB da agroindústria}

No segmento industrial, é incluído todo o valor adicionado pela agroindústria processadora. Os PIBs das indústrias de beneficiamento e processamento são calculados por:

$$
P I B_{j}^{I V}=V A_{j}
$$

em que $j$ representa as atividades industrias sob análise.

Para a indústria de beneficiamento do algodão considera-se a fabricação de fios e tecidos de têxteis naturais, excluindo-se, assim, a parcela da indústria de fios sintéticos. Ademais, no segmento industrial da cadeia do algodão também se considera a produção de óleos de algodão.

\subsubsection{PIB da Distribuição}

No cálculo do segmento de distribuição, computou-se a parcela dos valores adicionados pelos setores de Transporte, Comércio e Outros Serviços de Distribuição ligados à cadeia. Essa parcela é definida pela participação da demanda final sobre os produtos da cadeia do algodão, da demanda final doméstica (DFD). A demanda final dos produtos da cadeia do algodão inclui as demandas das atividades "dentro da porteira" e agroindústrias relacionadas.

O segmento "Outros Serviços de Distribuição" representa todos os demais serviços (que não Transporte e Comércio) utilizados pela cadeia produtiva do algodão. Estão incluídos neste segmento os serviços de produção e distribuição de eletricidade, gás, água, esgoto e limpeza urbana, serviços de informação, Intermediação financeira, seguros e previdência complementar e serviços relacionados, Atividades imobiliárias e aluguéis, serviços de manutenção e reparação, serviços de alojamento e alimentação e serviços prestados às empresas.

A expressão abaixo representa a operação realizada para o cômputo do PIB dadistribuição.

$$
P I B^{I V}=\left(\frac{D F D_{J}}{D F D}\right)\left[\sum_{m} V A_{m}\right]+\sum_{m}\left[c t_{m j} \times V A_{m}\right]
$$


em que $j$ representa os produtos da cadeia (primário e industrial);m representa as atividadesde transporte, comércio e outros serviços. O termo $D F D$ refere-se ao valor da demanda final portodos os bens e serviços da economia e $D F D_{j}$ representa a demanda final dos produtos da cadeia analisada.

Além da parcela da renda dos setores de Distribuição realizados com as atividades "pós-porteira", computa-se também uma parcela da rendarelativa aDistribuiçãono segmento de insumos $\left(c t_{m j} V A_{m}\right)$.

\subsubsection{PIB total da cadeia}

Com base nos procedimentos de cálculo apresentados, os resultados do PIB para a cadeia do algodãopodem ser expressos da seguinte forma:

$$
P I B=P I B^{I}+P I B^{I}+P I B^{I I I}+P I B^{I V}
$$

em queI, II, III e IV correspondem aos segmentos de insumos, primário, agroindústria e distribuição, respectivamente.

\subsection{Evolução do PIB para os demais anos}

As estimativas do PIB da cadeia do algodão, segundo os segmentos que a compõem, para os demais anos (que não o período-base de 2007), foi realizada a partir da evolução das receitas com os produtos e despesas com insumos que cada segmento adquire na mesma cadeia ou nas demais cadeias da economia como um todo. Para tanto, foram empregados indicadores de preços e quantidades ligados a cada segmento (Insumos, Básico e Indústria). No caso do segmento de Serviços, em função da própria metodologia, seu desempenho anual é vinculado não apenas à receita dos setores de comércio/ transporte, mas também à receita dos segmentosa montante relacionados às atividades primária e industrial.O Quadro 1apresenta, de forma resumida,o conjunto de produtos e suas respectivas fontes de dados. 
Quadro 1 - Produtos e Fontes utilizadas para evolução anual das receitas e despesas da cadeia

\begin{tabular}{|llll|}
\hline Segmentos & Produtos & Fonte dos Preços & Fonte dos Volumes \\
\hline \multirow{4}{*}{ Insumos } & Sementes & IEA & ABRASEM \\
& Óleo Diesel & ANP & ANP \\
& Fertilizantes & DERAL & ANDA \\
& Defensivos & ANDEF & ANDEF \\
\hline \multirow{2}{*}{ Agropecuária } & Pluma & CEPEA & CONAB \\
& Caroço & CEPEA & CONAB \\
\hline \multirow{2}{*}{ Agroindústria } & Fios e Tecidos & FGV & IBGE \\
& Óleo & CEPEA & IBGE \\
\hline \multirow{2}{*}{ Distribuição } & Comércio/transporte & CEPEA & CONAB \\
& Demais Serviços & - & - \\
\hline
\end{tabular}

Fonte: Elaboração própria

\section{RESULTADOS E DISCUSSÕES}

A cadeia produtiva do algodão contempla o conjunto de atividades que tem nesse produto agrícola sua principal matéria-prima. Sua extensão abrange desde os insumos usados na produção agrícola do algodão, passando pelaprodução de óleo e de fios e tecidos de fibras de algodão e por fim, pela distribuição destes produtos até o consumidor final.

O algodão é a principal matéria-prima da produção de têxteis no Brasil e representa aproximadamente $98 \%$ das fibras naturais utilizadas na produção de fios, tecidos, confecções, filamentos, linhas de costura e outras manufaturas. Sua cadeia produtiva abrange diversos segmentos que empregam e/ou fornecem ocupação, desde o campo até a indústria e os serviços. Esses elospodem diferir de acordo com a tecnologia, o tamanho e o grau de integraçãoadotado.

O sistema de produção do algodão pode variar quanto à colheita, ao descaroçamento (beneficiamento da pluma) e aos sistemas de classificação visual ou com equipamentos (High Volume Instruments - HVI). A fiação e a tecelagem têm arranjos de "governança" distintos, pois enquanto a fiação está calcada na produção em escala e, em geral, é mais bem organizada politicamente, a tecelagem é atomizada e não dispõe de representatividade 
institucional. A "governança” do setor de vestuário é exercida por empresas de varejo, enquanto na cotonicultura (produção agrícola)as instituições públicas desempenham importante papel na regulação dos fluxos de produção e regras que condicionam o mercado (MAPA, 2007).

Segundo o MAPA (2007), os avanços tecnológicos na cotonicultura, em especialdurante a década de 1990, levaram o setor a padrões de produtividade da terra, do capital e da mão de obra comparáveis aos mais eficientes do mundo. Ademais,o avanço tecnológico, através da colheita mecanizada, abriu caminho para que grandes produtores encontrem no algodão uma alternativa à plantação de soja e outros grãos. Nas grandes plantações, a mecanização une maior qualidade e maiores rendimentos com significativo diferencial de despesas e economias de escala (Deser, 2007). Ao final, uma das principais consequências destas mudanças refere-se às possibilidades de concentração da produção em propriedades com maior capacidade produtiva. Segundo o último Censo Agropecuário, aproximadamente 6.300 estabelecimentos produziram algodão herbáceo em 2006, o que representou $0,2 \%$ dos estabelecimentos agropecuários do país. A área utilizada na produção nacional de algodão em 2007, foi de 1,1 milhão de hectares, de onde foram colhidas 4,1 milhões de toneladas de algodão herbáceo em caroço e gerados $\mathrm{R} \$ 3,9$ bilhões em receitas para os produtores (4,4\% do total das lavouras temporárias).

Desde final da década de 1990, a produção de algodão no Brasil passou a contar com grandes propriedades. Estas unidades produtivas possuem sua própria estrutura de processamento primário (separação da pluma do caroço e enfardamento da pluma) e negociam diretamente com as indústrias ou mesmos realizam a exportação de seus produtos (Deser, 2007).

Segundo Alves (2006), outro ponto a destacar é a colheita mecânica que predomina atualmente, ao contrário do que ocorria até meados da década de 1990. Mesmo os pequenos produtores localizados nas regiões tradicionais estão alugando máquinas de proprietários das demais regiões para efetuarem a colheita, reduzindo-se os custos e obtendo-se um produto de melhor qualidade, assim como tem grande importância para a homogeneidade da pluma. De modo geral, também se observou a verticalização do processo produtivo e de beneficiamento por parte dos médios e grandes produtores, agregando-se valor ao produto e eliminando-se a intermediação. 
Esta reestruturação não chegou ao pequeno produtor, devido a restrições de crédito, à instabilidade de preços e ao não recebimentodo produto levando em consideração sua qualidade (HVI).

Com base no ano de 2007, foram realizadas as estimativas de PIB da cadeia do algodão para os anos a montante de 2001 a 2006 e a jusante de 2008 a 2011, sendo estas apresentadas na Tabela 1. O PIB do conjunto dessacadeia produtiva apresentou oscilações durante os anos em análise. O maior valor do PIB da cadeia foi observado em 2004 (R \$ 36,9 bilhões) e o menor, $\mathrm{R} \$ 15,8$ bilhões, em 2009.

Tabela 1. PIB da cadeia do Algodão de2001 a 2011 (R \$ milhões a preços de 2010)

\begin{tabular}{lrrrrr}
\hline & Insumos & Primário & Agroindústria & Serviços & Total da Cadeia \\
\hline 2001 & 299,25 & $2.271,07$ & $20.037,03$ & $4.956,99$ & $27.564,34$ \\
2002 & 271,70 & $2.291,60$ & $21.344,73$ & $5.178,86$ & $29.086,89$ \\
2003 & 392,73 & $2.948,50$ & $23.772,03$ & $5.726,76$ & $32.840,01$ \\
2004 & 552,08 & $4.179,02$ & $26.228,14$ & $5.927,89$ & $36.887,14$ \\
2005 & 431,42 & $2.228,55$ & $23.747,11$ & $6.124,20$ & $32.531,28$ \\
2006 & 408,93 & $1.833,96$ & $20.066,96$ & $5.876,40$ & $28.186,26$ \\
2007 & 459,91 & $2.964,00$ & $16.206,22$ & $6.021,12$ & $25.651,25$ \\
2008 & 446,79 & $3.080,45$ & $10.811,02$ & $5.718,85$ & $20.057,12$ \\
2009 & 397,50 & $1.621,79$ & $8.527,37$ & $5.211,42$ & $15.758,08$ \\
2010 & 446,73 & $2.748,15$ & $11.028,35$ & $5.361,79$ & $19.585,02$ \\
2011 & 546,79 & $7.477,96$ & $6.476,60$ & $5.052,47$ & $19.553,83$ \\
\hline
\end{tabular}

Fonte: Cepea-USP e CNA

O início dos anos 2000 foi marcado pela recuperação da produção nacional de algodão, o que reduziu significativamente as importações do país e aumentou suas exportações. Em relação ao PIB da cadeia, pode-se observar três grandes ciclos. O primeiro, entre os anos de 2001 e 2004, foi de expressivo crescimento: alta de aproximadamente 30\% (Tabela 2). Este desempenho esteve ligado ao crescimento do segmento Industrial que, refletindo a ascensão dos preços dos fios naturais, obteve maiores receitas. Em 2004, a renda da cadeia fechou em R \$ 36,9 bilhões.

$\mathrm{O}$ ano de 2005 marcou o início do segundo ciclo. O desempenho negativo nos segmentosde insumos, primário e de processamento foi responsável 
pelo recuo. Com isso, a renda da cadeia se reduziu para $\mathrm{R} \$ 32,5$ bilhões. Daí em diante o PIB seguiu em franca queda, fechando o ano de 2009 em R \$ 15,8 bilhões. Em 2010, a retomada do crescimento marcou o terceiro ciclo, e a rendada cadeia do algodão atingiu R\$19,6 bilhões.Já em 2011, o forte crescimento do segmento primário, puxado pela demanda mundial, foi neutralizado pelo desempenho da indústria que sofreu com a concorrência dos fios sintéticos e das importações. No balanço anual, a renda da cadeia se manteve estável.

Tabela 2. Taxas de crescimento do valor real dos PIBs dos segmentos da cadeia do Algodão (\%)

\begin{tabular}{lrrrrr}
\hline & & & & & Total da \\
& Insumos & Primário & Agroindústria & Distribuição & Cadeia \\
\hline $2002 / 01$ & $-9,21$ & 0,90 & 6,53 & 4,48 & 5,52 \\
$2003 / 02$ & 44,55 & 28,67 & 11,37 & 10,58 & 12,90 \\
$2004 / 03$ & 40,58 & 41,73 & 10,33 & 3,51 & 12,32 \\
$2005 / 04$ & $-21,86$ & $-46,67$ & $-9,46$ & 3,31 & $-11,81$ \\
$2006 / 05$ & $-5,21$ & $-17,71$ & $-15,50$ & $-4,05$ & $-13,36$ \\
$2007 / 06$ & 12,47 & 61,62 & $-19,24$ & 2,46 & $-8,99$ \\
$2008 / 07$ & $-2,85$ & 3,93 & $-33,29$ & $-5,02$ & $-21,81$ \\
$2009 / 08$ & $-11,03$ & $-47,35$ & $-21,12$ & $-8,87$ & $-21,43$ \\
$2010 / 09$ & 12,39 & 69,45 & 29,33 & 2,89 & 24,29 \\
$2011 / 10$ & 22,40 & 172,11 & $-41,27$ & $-5,77$ & $-0,16$ \\
\hline Acum. 11/01 & 82,72 & 229,27 & $-67,68$ & 1,93 & $-29,06$ \\
\hline
\end{tabular}

Cepea-USP e CNA

As variações das receitas e das despesas dos segmentos primário e agroindustrial da cadeia do algodão (Tabela 3) ajudam a melhor entender os resultados acima encontrados. Ressalta-se que, no caso dos segmentos de Insumos e de Distribuição, não são apresentadas tais informações pelo fato de o desempenho destes segmentos serem avaliados pelo crescimento real do valor bruto da produção e não pelo diferencial entre receitas e despesas. Isso se deve à dificuldade em se delimitar, de forma adequada, as despesas destes segmentos.

Em 2002, o aumento da renda do segmento industrial refletiu o recuo das despesas, paralelo a uma receita estável. Este resultado repercutiu sobre o 
PIB da cadeia e, com isso, a renda elevou-separa $\mathrm{R} \$ 29,1$ bilhões ao final do ano. Em 2003 e 2004, os preços e volumes em ascensão seguiram elevando a renda dos segmentos primário e de processamento. Nestes dois anos, o PIB cresceu em torno 25\%, fechando o período (2004)em R $\$ 36$,9bilhões.

Para MAPA (2005), o aumento nos preços da fibra de algodão em 2003 favoreceu o aumento daárea cultivada entre 2003 e 2004, o que resultou em aumento da produção superior ao consumo em 2004, e o consequente aumento do estoque final. $\mathrm{O}$ aumento do preço de fibrade algodão em 2003 foi superior ao das fibras sintéticas, reduzindo a competitividade dafibra de algodão e, a despeito do aumento significativo no consumo de fibra de algodão em2003, houve redução no preço em 2004.

Em 2005, o PIB voltou a recuar, refletindo o desempenho negativo nos segmentos primário e industrial. Este desempenho foi ocasionado pelo recuo de preços paralelo ao volume da safra colhido,devido às baixas precipitações associadas a altas temperaturas e ao baixo nível detecnologia.

Tabela 3. Variações das Despesas e Receitas das atividades Primária e Industrial da Cadeia do Algodão (\%)

\begin{tabular}{lrrrrr}
\hline & \multicolumn{2}{c}{ Primário } & & \multicolumn{2}{c}{ Agroindústria } \\
\cline { 2 - 3 } \cline { 5 - 6 } $2002 / 01$ & Despesas & Receitas & & Despesas & Receitas \\
\cline { 2 - 3 } \cline { 5 - 6 } $2003 / 02$ & $-8,91$ & $-3,34$ & & $-4,03$ & 0,95 \\
$2004 / 03$ & 41,56 & 33,92 & & 6,97 & 9,16 \\
$2005 / 04$ & 35,81 & 39,18 & & 10,26 & 10,30 \\
$2006 / 05$ & $-21,64$ & $-36,15$ & & $-3,36$ & $-6,46$ \\
$2007 / 06$ & $-4,75$ & $-11,02$ & & 3,20 & $-5,99$ \\
$2008 / 07$ & 18,25 & 37,66 & & 4,33 & $-6,09$ \\
$2009 / 08$ & $-0,11$ & 2,01 & & 5,14 & $-9,47$ \\
$2010 / 09$ & $-14,67$ & $-32,17$ & & $-8,69$ & $-12,17$ \\
$2011 / 10$ & 20,11 & 40,61 & & 8,05 & 13,41 \\
Cepea-USP e CNA & 24,84 & 98,58 & & & \\
\end{tabular}

Daí em diante, os recuos no PIB se tornaram consecutivos. As baixas na receita, em especial no segmento industrial, conduziram a tal resultado. Nesse cenário também pesou o recuo nos preços do algodão. Isso veio ocorrendo mesmo com a demanda sendo maior que aoferta do produto. A alta 
nas cotações do petróleo, matéria-prima utilizada na fabricação de tecidossintéticos, elevou a demanda por fibras de algodão. Entretanto, essa maior procura pelo algodão não proporcionou a recuperação esperada nos preços.

Após 2005, o efeito da liberalização dos mercados mundiais de têxteise vestuários sobre a produção primária esobre a indústria,foram sentidos ao redor de todo o mundo.O baixo custo damão de obra na China e Índia, paralelo à consolidação do Acordo de Têxteis e Vestuários, elevou o consumo de fibras de algodão com origem nestes países, provocando um descolamento das plantas industriais têxteis para estes países.No Brasil, a renda da cadeia do algodão seguiu recuando seguidamente, em especial devido à queda no segmento Industrial.Ainda assim, o Brasil se manteve entre os dez principais paísesprodutores e exportadores de algodão, segundo estatísticas da FAO (2012).

Em 2007, o bom desempenho dos volumes produzidos dentro da porteira culminou em aumento na receita do segmento primário, o que, ao final, impediu maior recuo no PIB da cadeia. De acordo com o IBGE, a extensão das lavouras brasileiras de algodão cresceu 24\% em 2007, o que refletiu em aumento de $42 \%$ no volume produzido do grão.

Nos demais anos, a baixa rentabilidade com a cultura, em relação aos grãos, se acentuou e, ao final de 2009, o PIB não ultrapassou R\$ 17,8 bilhões.Esse desempenho ruim refletiu diretamente sobre a área plantada de algodão,que entre 2008 e 2009, caiu de aproximadamente 30\%. Paralelamente ocorreu um fortíssimo incremento nas importações anuais, tanto de fios como de tecidos, além de uma significativa diminuição nas exportações anuais de fios.

O PIB da cadeia voltou a subir apenas em 2010, ultrapassando R $\$ 18$ bilhões. Este resultado esteve atrelado aos excelentes preços apresentados pela pluma e pelos fios naturais, o que refletiu em significativo crescimento na receita do segmento primário. Com relação ao processamento, os volumes também cresceram, favorecendo as receitas. A demanda firme e baixa oferta ao longo de 2010 ocasionaram redução dos estoques de passagem, que chegaram à menor relação estoque/consumo dos últimos 15 anos. O crescimento da demanda foi reflexo do avanço da economia mundial, enquanto a redução da oferta esteve relacionada à menor área cultivada e à redução da produtividade em alguns importantes países produtores. Este cenário refletiu 
sobre os preços da pluma, que, em 2010, atingiram máximas históricas nos mercados interno (em termos nominais) e externo. O cenário de alta nos preços da pluma se estendeu até março de 2011, quando os preços começaram a desacelerar devido a recuperação da oferta, apresentando recuos ainda mais fortes no segundo semestre do ano; no entanto, ainda garantiram significativa renda ao produtor. A agroindústria, por sua vez, sofreu com a alta no preço da matéria-prima, o que incentivou a substituição dos fios de algodão por fios sintéticos e a importação da fibra e de produtos acabados.

$\mathrm{Na}$ Figura 1 são apresentadas as parcelas que cada segmento representou no PIB total anual da cadeia do algodão. As oscilações mais significativas ocorreram no segmento primário que, nos momentos de alta de preços, ganhou espaço em relação ao segmento Industrial. Mesmo assim, a indústria seguiu respondendo pela maior participação na renda durante todo o período, seguida do segmento de Distribuição. Na média do período, o segmento Insumos representou $2 \%$ do PIB da cadeia, o segmento dentro da porteira, $12 \%$, indústria, $63 \%$ e aDistribuição, $23 \%$.

Figura 1. Participações dos segmentos no PIB da cadeia do Algodão (\%)

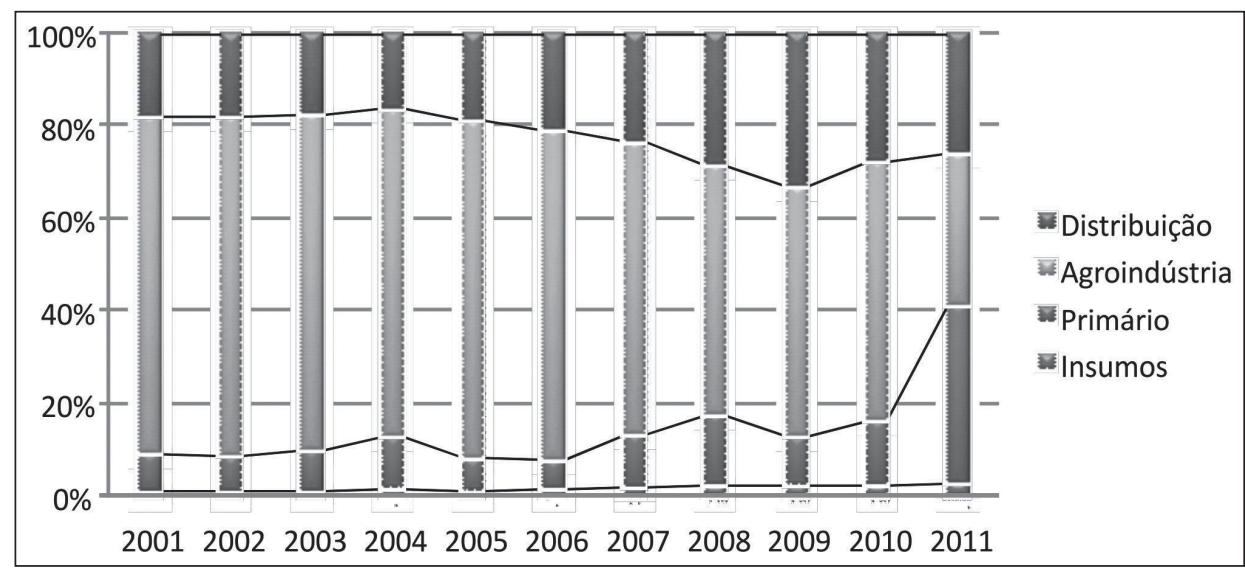

Cepea-USP e CNA

Dada a predominância da renda gerada no segmento agroindustrial,vale ressaltar que essa atividade inclui desde o beneficiamento do algodão, na algodoeira, até o consumo pelo setor industrial têxtil; assim, a renda nela gerada está ligada aos agentes que realizam o processamento do algodão. 
Como atualmente muitos produtores já efetuam o descaroçamento do algodão dentro da própria fazenda, parte da renda gerada no segmento industrial também é apropriada pelo produtor rural.

A mudança na participação do segmento agroindustrial também reflete a reestruturação da fabricação de têxteis no Brasil ao longo da década de 1990, em virtude da entrada no país dos produtos (fios) e mesmo de tecidos oriundos do sudeste asiático. Deste fato, houve um grande movimento de fusões e aquisições, que culminou num amplo processo de concentração desta indústria e na desestruturação do setor de máquinas para a indústria têxtil sendo que, na atualidade, praticamente todas as máquinas para esta indústria são importadas (Deser, 2007).

\section{CONCLUSÕES}

O objetivoprincipal desta pesquisa foi desenvolver um sistema de cálculo e estimar a renda da cadeia produtiva do algodão para os anos de 2001 a 2011. Na elaboração do cálculo da renda foram avaliados os valores gerados em cada segmento, ao longo de todo o período.

Como se pôde observar no período de análise, a cadeia do algodão teve seu produto em ascensão entre os anos de 2001 e 2004, quando a renda atingiu $\mathrm{R} \$ 36,8$ bilhões (a preços de 2010); maior valor em todos os anos analisados.Esse desempenho se explica pelo aquecido cenário da economia mundial em 2003 e 2004, o que implicou em aumento da produção e doconsumo de têxteis e vestuário, favorecendo tanto a produção quanto o consumo de fibra de algodão. Nesse período as despesas se elevaram, mas as receitas obtidas foram ainda maiores.

A partir de então, a agregação de valor da cadeia esteve em queda até 2009 quando a renda gerada pela cadeia chegou a R \$ 15,8 bilhões. Esse movimento de retração ocorreu em praticamente todos os segmentos da cadeia, mas em especial no industrial que viu suas receitas recuarem consecutivamente. Dos $\mathrm{R} \$ 26,2$ bilhões e participação de $71,1 \%$ na renda da cadeia em 2004, esses valores recuaram para $\mathrm{R} \$ 8,5$ bilhões e 54,1\% (em termos reais). Nos últimos dois anos, houve recuperação de parte da renda, com crescimento em 2010 e novo recuo em 2011. Os preços da pluma tiveram intensa alta, melhorando as receitas do setor primário, mas, por outro lado, 
também impuseram aumento de custos ao setor de processamento. Diante da alta de preços da matéria-prima, a agroindústria passou a substituir os fios de algodão por fios sintéticos e a importação da fibra e de produtos acabados.

No balanço do período em análise, se observou uma ampliação da renda no segmento primário e de insumos, queda no segmento industrial e manutenção do segmento de distribuição. No segmento primário, a produção de algodão no Brasil passou a contar com grandes propriedades, com colheita mecânica, estrutura própria de processamento e negociação direta com as indústrias ou mesmo exportação, eliminando-sealguns elos de intermediação. Isso fez elevar a agregação de valor "dentro da porteira" em $229,3 \%$ nos dez anos. Por outro lado, a agroindústria, tendo de enfrentar insumos mais caros e maior concorrência internacional dos produtos sintéticos, reduziu sua participação na cadeia e no valor agregado, com queda de $67,7 \%$ na renda gerada no acumulado dos dez anos.

Para os próximos anos, o cenário de aumento das exportações brasileiras de algodão em pluma está atrelado à elevação da demanda internacional, principalmente da China (FIESP, 2012). Segundo as estimativas do FAPRI -ISU (2010), as importações chinesas de algodão em pluma atingirão 3,7 milhões em 2019/2020, o que representa um aumento de $45 \%$ com relação às exportações observadas em 2010/2011 (FIESP, 2012).

Estes resultados, ao revelarem particularidades envolvidas na cadeia, podem ser usados como auxílio no melhor entendimento das necessidades do setore, por conseguinte, no direcionamento eficiente de ações e políticas que visem avanços no desempenho do agronegócio brasileiro.

\section{EVOLUTION OF COTTON'S PRODUCTIVE CHAIN IN GDP DURING 2000 DECADE}

\section{Abstract}

The 2000s marked an important cycle of growth in the Brazilian economy, culminating, however, with the 2009 financial crisis. In the cotton production chain, structural changes on the production side and greater trade openness imposed changes in the competitive market, affecting major adjustments. To understand the impact of this scenario, this paper 
carried out the calculation of the GDP of the cotton production chain, between the years 2001 and 2011, exploring the changes observed in each chain segment. The results showed losses from 2004 on, with significant increase in participation of the primary sector in the economic value added, while industrial output lost income and participation in the whole chain.

Keywords: cotton, supply chain, income.

JEL Classification: Q13.

\section{REFERÊNCIAS}

ASSOCIAÇÃO BRASILEIRA DA INDÚSTRIA TÊXTIL E DE CONFECÇÕES. Disponível em:<http://www.abit.org.br>. Acesso em: 16 dez 2011.

ALVES, L.R.A. A reestruturação da cotonicultura no Brasil: fatores econômicos, institucionais e tecnológicos. Piracicaba, 2006. 121p. Tese (doutorado). Escola Superior de Agricultura "Luiz de Queiroz". Universidade de São Paulo.

ASSOCIAÇÃO NACIONAL PARAA DIFUSÃO DE ADUBOS - ANDA. Anuário Estatístico do Setor de Fertilizantes. São Paulo:ANDA, 2009. 157 p.

ASSOCIAÇÃO BRASILEIRA DAS INDÚSTRIAS DE ÓLEOS VEGETAIS - ABIOVE.Distorções tributárias na Indústria de Óleos Vegetais. Brasília, 2008. Disponível em <http://www.abiove.com.br/palestras/abiove_palestra_mdic_ago08.pdf $>$. Acesso em: 22 de jul. de 2009.

DEPARTAMENTO DE ESTUDOS SÓCIO-ECONÔMICOS - DESER. A Cadeia Produtiva do Algodão: Estudo Exploratório. Curitiba, 2007. Disponível em: $<$ http://www.deser.org.br/pub_read.asp?id=116>. Acesso em 05 de nov. de 2009.

FEDERAÇÃO DAS INDÚSTRIAS DO ESTADO DE SÃO PAULO FIESP. Agronegócio Brasileiro: Características, Desempenho, Produtos 
e Mercados. São Paulo, 2008. Disponível em <http://www.fiesp.com.br/ agencianoticias/2008/05/07/rev_agronegócio.pdf $>$.Acesso em: $10 \mathrm{de}$ fev. de 2010 .

INSTITUTO BRASILEIRO DE GEOGRAFIA E ESTATÍSTICA - IBGE. Sistemas de Contas Nacionais, 2007. Rio de janeiro, 2008.

INSTITUTO BRASILEIRO DE GEOGRAFIA E ESTATÍSTICA - IBGE. Produção Industrial Anual, 2007. Rio de janeiro, 2009. Disponível em $<$ http://www.ibge.gov.br/home/estatistica/economia/industria/pia/empresas/2007/defaultempresa.shtm> Acesso em: 14 de ago. de 2009.

GUILHOTO, J.J.M.; FURTUOSO, M.C.O.; BARROS, G.S. de C. Oagronegócio na economia brasileira, 1994 a 1999. Piracicaba: CEPEA-USP, set. 2000.139 p. Disponível em: <http://www.cepea.esalq.usp.br/pib/other/ relatorio_metodologico.pdf $>$. Acesso em: 10 de maio de 2010.

GUILHOTO, J. J. M.; SESSO FILHO, U. A. Estimação da matriz de insumo-produto a partir de dados preliminares das contas nacionais. Economia Aplicada, v. 9, n. 2, p. 277-299, abr./jun. 2005.

MINISTÉRIO DAAGRICULTURA, PECUÁRIA E ABASTECIMENTO MAPA. Séries Agronegócios. Disponível em: $<$ http://www.agricultura.gov. br/portal/page?_pageid $=33,6841102 \& \_d a d=$ portal\&_schema $=$ PORTAL $>$. Acesso em 13 de out. de 2009. 